\title{
CHARACTERIZATION OF ORTHOSIPHON STAMINEUS BENTH EXTRACTS BY REVERSED-PHASE THIN LAYER CHROMATOGRAPHIC METHODS
}

\author{
NELI-KINGA OLAH ${ }^{\mathrm{a}, \mathrm{b}}$, DANIELA HANGANU ${ }^{\mathrm{c}}$, EDE BODOKI ${ }^{\mathrm{c}}$, RADU \\ OPREAN ${ }^{c}$, CLAUDIA TOMA ${ }^{a}$, CLAUDIU MORGOVAN ${ }^{a}$, ELISABETA CHIȘE ${ }^{a}$, \\ ANDREEA BRAȘOVAN ${ }^{\mathrm{d}}$, SIMONA CODRUȚA AURORA COBZAC ${ }^{\mathrm{e}^{*}}$ \\ SIMION GOCAN
}

\begin{abstract}
TLC is a powerful method used for separation of complex mixtures such as plant extracts. Employing different TLC techniques the separations can be improved. This paper presents a study of the Orthosiphon stamineus Benth extracts using isocratic reversed-phase thin layer chromatography (RP-TLC) and reversed-phase automated multiple development technique (RP-AMD). Methanol (SI) and a mixture of methanolwater-methyl acetate (SII) were used as extraction agents. Orthosiphon stamineus Benth. belongs to the Lamiaceae family. Its leaves contain rosmarinic acid, sinesetine and eupatorine as main compounds. After TLC separation the bioactive compounds from plant extracts were identified by comparison of the $\mathrm{R}_{\mathrm{f}}$ values and in situ UV-Vis spectra with those of the standards and quantified using the calibration method. The rosmarinic acid was better extracted in the solvent mixture methanol-water-methyl acetate $(10: 10: 80, v / v)$, while the sinesetine and eupatorine, which are more lipophilic, were better extracted in methanol. The study revealed the AMD technique superiority in comparison with the isocratic one.
\end{abstract}

Keywords: RP-TLC; RP-AMD; Orthosiphon stamineus Benth. extracts; rosmarinic acid; sinesetine; eupatorine.

\footnotetext{
a "Vasile Goldis" Western University of Arad, Faculty of Pharmacy, 86 L. Rebreanu str., Arad, Romania

${ }^{\text {b }}$ SC PlantExtrakt SRL, 407059 Rădaia. Cluj, Romania

c "Iuliu Hațieganu" University of Medicine and Pharmacy from Cluj-Napoca, Faculty of Pharmacy, 8 Victor Babeș str., Cluj-Napoca, Romania

*Corresponding authors: danahcluj@gmail.com, csimona@chem.ubbcluj.ro

d Babeş-Bolyai University of Cluj-Napoca, 1 Kogălniceanu Str., Cluj-Napoca, Romania

e Babeş-Bolyai University of Cluj-Napoca, Faculty of Chemistry and Chemical Engineering, 11 Arany Janos Str., Cluj-Napoca, Romania
} 
N.-K. OLAH, D. HANGANU, E. BODOKI, R. OPREAN, C. TOMA, C. MORGOVAN, E. CHIȘE, A. BRAȘOVAN, S. C. A. COBZAC, S. GOCAN

\section{INTRODUCTION}

Orthosiphon stamineus Benth. belongs to the Lamiaceae family and it is originary from Southeast Asia. Orthosiphonis folium was used from long time in different kidney diseases. The vegetal product contains caffeic acid derivatives (rosmarinic acid, cichoric acid, etc) and polymethoxylated flavonoids (sinesetine, eupatorine) [1,2]. Their structure is presented in figure 1.<smiles>COc1ccc(-c2cc(=O)c3c(O)c(OC)c(OC)cc3o2)cc1O</smiles>

Figure 1. Structure of rosmarinic acid (I), sinesetin (II) and eupatorin (III)

Different techniques are used for identification and determination of these compounds. Usually separation methods using both, column [3-5] and planar [6-9] chromatography are preferred. Generally thin layer analyses are carried out on silica plates. Spectrophotometric methods for determination of caffeic acid derivatives are also used [3].

TLC is a versatile method for separating multicomponent mixtures. The separating power of isocratic TLC can be enhanced by two-dimensional development, multiple or automated multiple development (ADM). The AMD technique uses a solvent gradient and several development steps to separate compounds of widely different polarity. Most reported AMD applications have used gradients on normal phase plates [10-19].

This paper presents the qualitative and quantitative determination of rosmarinic acid, sinesetine and eupatorine from two extracts of Orthosiphon stamineus Benth. using isocratic RP-TLC and RP-AMD techniques. The identification of the separated compounds was performd based on chromatographic ( $R_{f}$ values) and non-chromatographic (in situ UV-Vis spectra) parameters. The efficiency of RP-TLC and RP-AMD separation techniques was achieved by comparison of $R_{f}$ values. On the other hand, based on quantitative analyses, the efficiency of the extraction systems was correlated with analytes polarity. 


\section{RESULTS AND DISCUSSION}

The chromatograms of developed plates using both chromatographic development methods RP-TLC and RP-AMD are presented in figure 2 and figure 3 respectively.

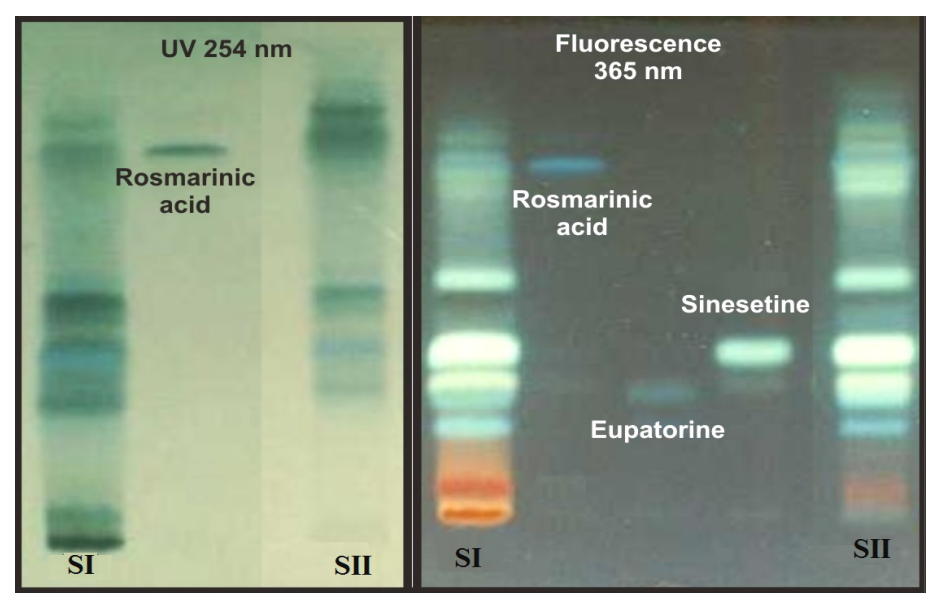

Figure 2. The chromatograms obtained using the isocratic technique

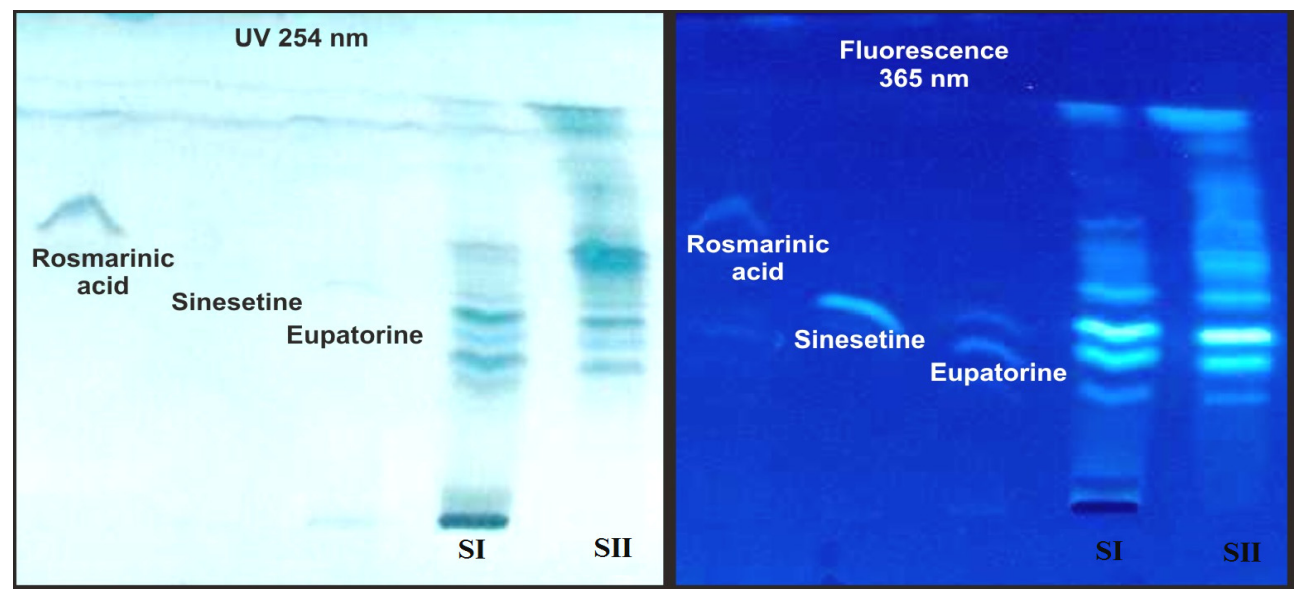

Figure 3. The chromatograms obtained using the AMD technique

The photodesitograms obtained by scanning the plates at $254 \mathrm{~nm}$ in reflectance mode and at $400 \mathrm{~nm}$ in fluorescence mode (excitation wavelength at $365 \mathrm{~nm}$ ) are presented in Figures $4-6$. 
N.-K. OLAH, D. HANGANU, E. BODOKI, R. OPREAN, C. TOMA, C. MORGOVAN, E. CHIȘE, A. BRAȘOVAN, S. C. A. COBZAC, S. GOCAN
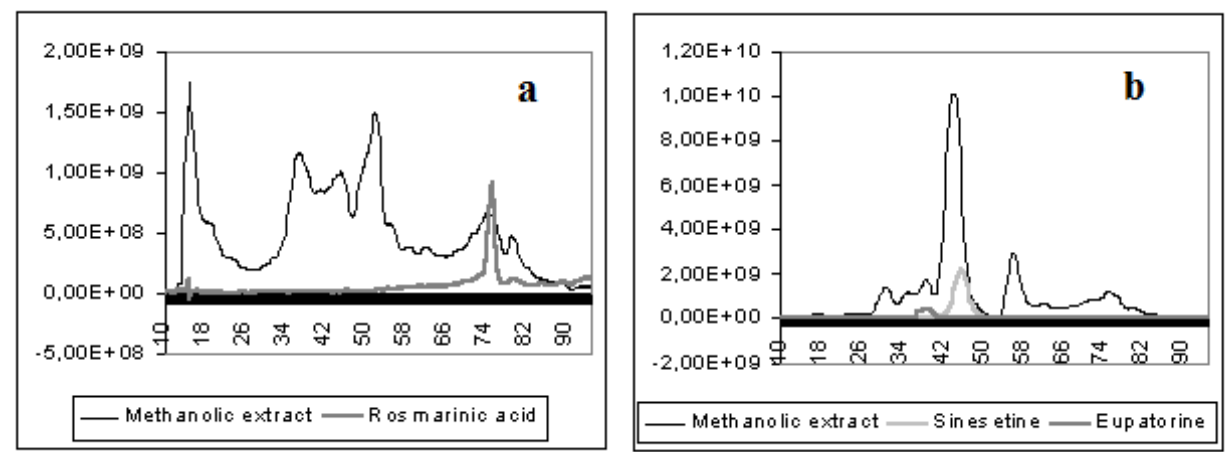

Figure 4. The densitogram of the methanolic extract (SI) separated by RP-TLC development. Visualization mode: (a) UV at $254 \mathrm{~nm}$; (b) fluorescence at $400 \mathrm{~nm}$.
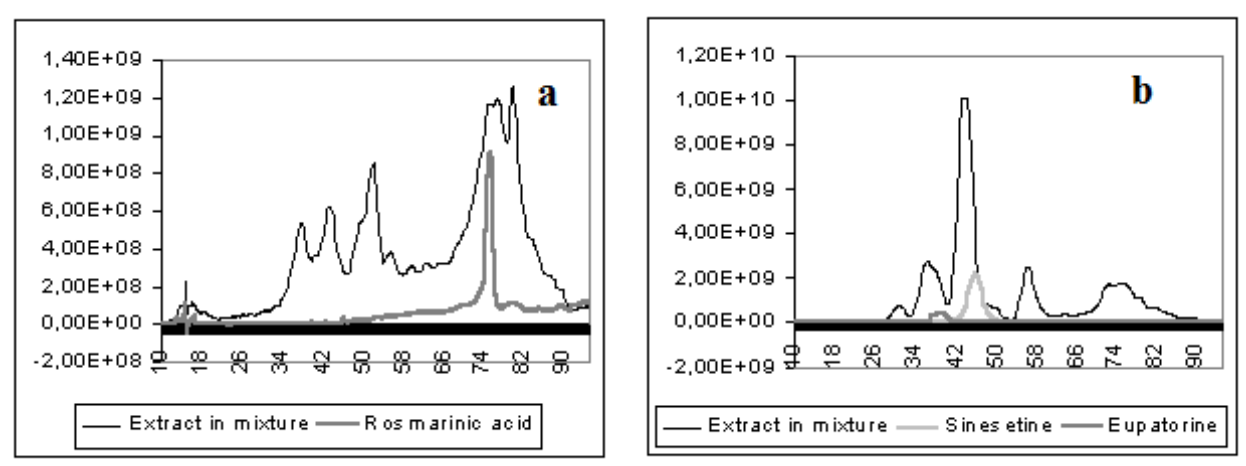

Figure 5. The densitogram of the solvent mixture extract (SII) separated by RP-TLC development. Visualization mode: (a) UV at $254 \mathrm{~nm}$, (b) fluorescence at 400nm
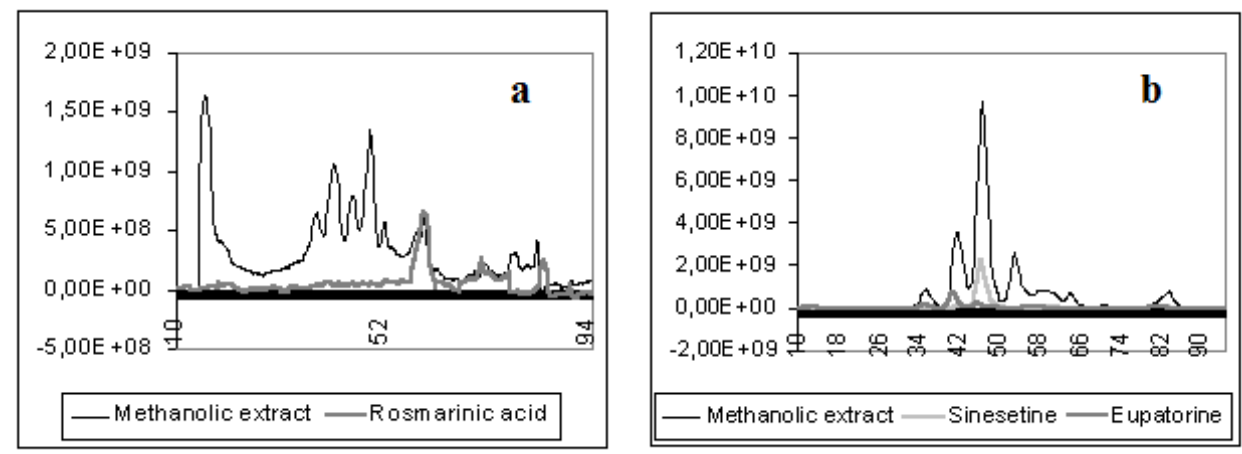

Figure 6. The densitogram of the methanolic extract (SI) separated by RP-AMD development. Visualization mode: (a) UV at $254 \mathrm{~nm}$; (b) fluorescence at $400 \mathrm{~nm}$. 

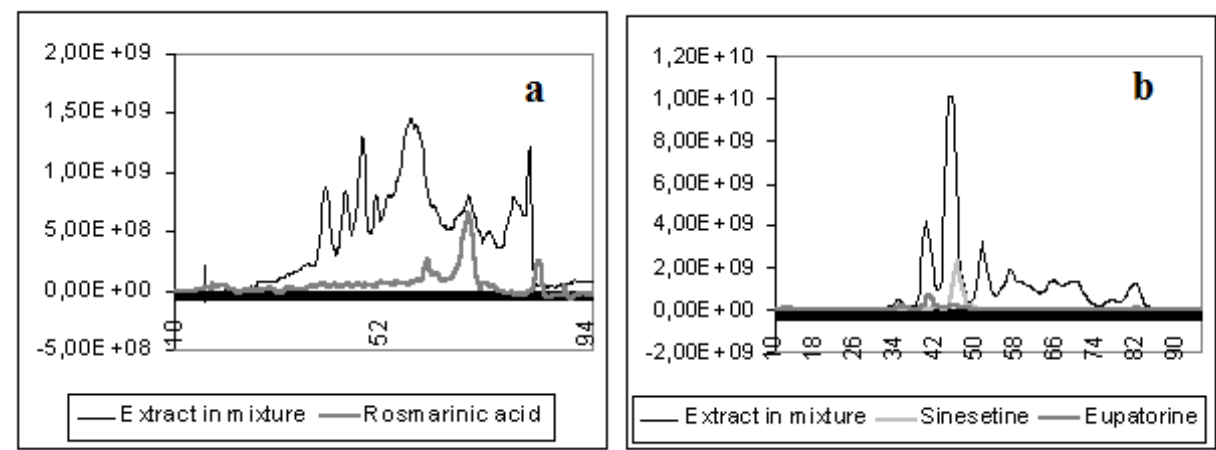

Figure 7. The densitogram of the solvent mixture extract (SII) separated by RP-AMD development. Visualization mode: (a) UV at $254 \mathrm{~nm}$, (b) fluorescence at 400nm.

Comparing the photodensitograms from Figure 4a with Figure $5 \mathrm{a}$ and Figure 6a with Figure 7a, respectively, it can be observed a difference between the polarities of extracted compounds. In methanol (SI) were extracted most non-polar compounds than by using the solvent mixture methanol - water - methyl acetate $(10: 10: 80$, v/v), which extracted more polar compounds. This observation is confirmed by a pronounced peak at the start line and also by decreasing the concentration of the more polar compounds that are located in the top area of the plate. Furthermore, it can be observed a good separation of rosmarinic acid, a more polar compound having a higher $R_{f}$ value, from sinesetine and eupatorine - less polar compounds that are situate in the middle zone of the plate.

On the other hand, comparing photodensitograms obtained by RPAMD developing method with than obtained by RP-TLC, it can be observed a better separation efficiency achieved with the first mentioned technique.

Moreover, comparison of figures $4 a$ with $6 a$ and $5 a$ with $7 a$, respectively, it can be observed an increased number of separated compounds obtained by RP-AMD vs RP-TLC method. The RP-AMD method gives a more specific fingerprint for plant extracts.

Another important observation is that fluorescence densitometry at $400 \mathrm{~nm}$ has a higher specificity than UV at $254 \mathrm{~nm}$. Having natural fluorescence, sinesetine and eupatorine can be selectively identified by fluorescence photodensitometry.

The interest compounds from extracts were identified based on chromatographic parameter - $R_{f}$, which are similar with the standards ones, in both visualization modes - fluorescence and fluorescence quenching (Table 1). 
N.-K. OLAH, D. HANGANU, E. BODOKI, R. OPREAN, C. TOMA, C. MORGOVAN, E. CHIȘE, A. BRAȘOVAN, S. C. A. COBZAC, S. GOCAN

Table 1. The $R_{f}$ value of the separated compounds

\begin{tabular}{|c|c|c|c|}
\hline Compound & Extract type & RP-TLC & RP-AMD \\
\hline \multirow{3}{*}{ Rosmarinic acid } & Standard & 0.94 & 0.73 \\
\cline { 2 - 4 } & Methanolic extract & 0.93 & 0.73 \\
\cline { 2 - 4 } & Extract in solvent mixture & 0.94 & 0.73 \\
\hline \multirow{3}{*}{ Sinesetine } & Standard & 0.54 & 0.43 \\
\cline { 2 - 4 } & Methanolic extract & 0.53 & 0.44 \\
\cline { 2 - 4 } & Extract in solvent mixture & 0.54 & 0.43 \\
\hline \multirow{3}{*}{ Eupatorine } & Standard & 0.45 & 0.35 \\
\cline { 2 - 4 } & Methanolic extract & 0.46 & 0.36 \\
\cline { 2 - 4 } & Extract in solvent mixture & 0.45 & 0.34 \\
\hline
\end{tabular}

Moreover, in situ UV-Vis spectra between 200 - $500 \mathrm{~nm}$ were register for spots having the same $R_{f}$. The spectra of the standards (rosmarinic acid, sinesetine and eupatorine) and their corresponding spots from both extracts are showing similar shapes (Figures 8-10).

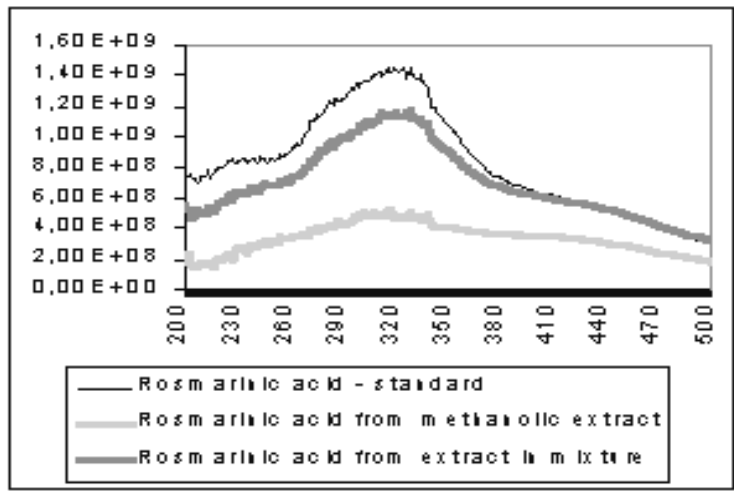

Figure 8. In situ UV-Vis spectra for rosmarinic acid (RP-AMD separation)

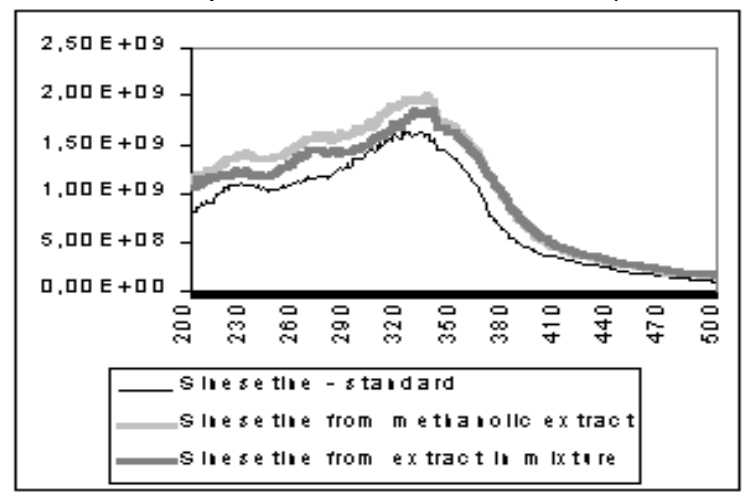

Figure 9. In situ UV-Vis spectra for sinesetine (RP-AMD separation) 


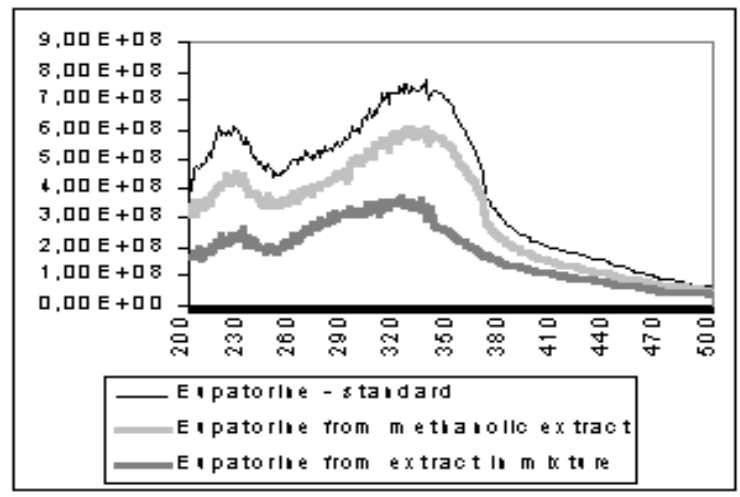

Figure 10. In situ UV-Vis spectra for eupatorine (RP-AMD separation)

Quantitative determination of the analytes was carried out by scanning the RP-TLC plates at $254 \mathrm{~nm}$. The calibration functions were obtained by linear regression. Linear relationships between area $(\mathrm{Y})$ and analyte quantity/spot (X) were obtained (Table 2).

Table 2. Calibration curves parameters

\begin{tabular}{|l|c|c|c|}
\hline Compound & Rosmarinic acid & Sinesetin & Eupatorin \\
\hline $\begin{array}{l}\text { Working range } \\
\text { concentration (mg/ml) }\end{array}$ & $0.108-0.540$ & $1.500-6.000$ & $1.050-4.200$ \\
\hline $\begin{array}{l}\text { Working range } \\
(\mu \mathrm{g} / \mathrm{spot})\end{array}$ & $1.1-5.5$ & $15.0-60.0$ & $10.5-42.0$ \\
\hline Slope $\left( \pm \mathrm{t}^{*} \mathrm{~s} / \mathrm{n}^{1 / 2}\right)$ & $3914.80( \pm 947.62)$ & $2690.90( \pm 109.75)$ & $576.84( \pm 100.91)$ \\
\hline Intercept $\left( \pm \mathrm{t}^{*} \mathrm{~s} / \mathrm{n}^{1 / 2}\right)$ & $714.32( \pm 339.44)$ & $3134.50( \pm 416.25)$ & $207.72( \pm 267.85)$ \\
\hline $\mathrm{r}$ & 0.989 & 0.999 & 0.994 \\
\hline
\end{tabular}

The percent content $(\% \mathrm{mg} / \mathrm{g})$ of rosmarinic acid, sinesetin, and eupatorin in the studied plant, computed based on measured spot area and the equation of calibration curve, taking in account the extract volume and the analyzed quantity of the dry plant are presented in Table 3.

The extraction yield of rosmarinic acid - a hydrophilic compound, was higher when SII extraction system was used. On the other hand, when methanol was used, more lipophilic compounds like sinesetin and eupatorin are favored.

Tabel 3. The contenf of rosmarinic acid, sinesetine, and eupatorine in Orthosiphon stamineus Benth.

\begin{tabular}{|c|c|c|}
\hline $\begin{array}{c}\text { Rosmarinic acid } \\
\% \mathrm{mg} / \mathrm{g}\left( \pm \mathrm{t}^{*} \mathrm{~s} / \mathrm{n}^{1 / 2}\right)\end{array}$ & $\begin{array}{c}\text { Sinesetine } \\
\% \mathrm{mg} / \mathrm{g}\left( \pm \mathrm{t}^{*} \mathrm{~s} / \mathrm{n}^{1 / 2}\right)\end{array}$ & $\begin{array}{c}\text { Eupatorine } \\
\% \mathrm{mg} / \mathrm{g}\left( \pm \mathrm{t}^{*} \mathrm{~s} / \mathrm{n}^{1 / 2}\right)\end{array}$ \\
\hline \multicolumn{3}{|c|}{ Methanolic extract $(\mathrm{SI})$} \\
\hline $0,021 \pm(0,0004)$ & $0,852 \pm(0,0154)$ & $0,424 \pm(0,0071)$ \\
\hline \multicolumn{3}{|c|}{$\begin{array}{c}\text { Extract in solvent mixture }(\mathrm{SII}) \\
\text { methanol - water - methyl acetate }(1: 1: 8, \mathrm{v} / \mathrm{v})\end{array}$} \\
\hline $0,031 \pm(0,0006)$ & $0,837 \pm(0,0154)$ & $0,405 \pm(0,0071)$ \\
\hline
\end{tabular}


N.-K. OLAH, D. HANGANU, E. BODOKI, R. OPREAN, C. TOMA, C. MORGOVAN, E. CHIȘE, A. BRAȘOVAN, S. C. A. COBZAC, S. GOCAN

\section{CONCLUSIONS}

The two studied Orthosiphon stamineus Benth. extracts can be characterized using reversed phase - thin layer chromatography and automated multiple development on reversed phase, because the RP-TLC and RP-AMD techniques show good separation of the main compounds from Orthosiphon stamineus Benth. leaves. The separations with AMD technique were better than those with isocratic RP-TLC. The characterization of the studied extracts was performed by separation and identification of two main compound classes: the caffeic acid derivatives (rosmarinic acid) respectively the polymethoxylated flavonoids (sinesetine and eupatorine).

\section{EXPERIMENTAL SECTION}

\section{Materials, reagents and apparatus}

The experiment was perfromed using acetonitrile and methyl acetate obtained from Roth, (Germany), methanol supplied from Euromedica (Romania) and acetic acid from Chimopar (Romania). Rosmarinic acid (I) was supplied from Roth (Germany), sinesetine (II) and eupatorine (III) were obtained from Extrasynthese (France). Orthosiphon stamineus Benth. leaves were obtained from Caesar \& Loretz (Germany).

TLC RP18-Kiselgel $F_{254}(20 \times 20 \mathrm{~cm})$ plate used for chromatographic separation were purchased from Merck (Germany).

There were used a Desaga AS-30 automated applicator (Germany), a Camag AMD instrument (Muttenz Switzerland) and a Desaga CD 60 photodensitometer (Germany).

\section{Sample Preparation}

Bioactive compounds from $20 \mathrm{~g}$ crushed leaves of Orthosiphon stamineus Benth were extracted by cold extraction (10 days) with $100 \mathrm{~mL}$ extraction solvent. Two different systems were used for extraction: methanol (SI) and methanol-water-methyl acetate (10:10:80, v / v) mixture (SII). The second extraction system has already been optimized for a high yield of polyphenols extraction $[20,21]$. Both extracts were concentrated to $10 \mathrm{ml}$.

\section{Experimental Conditions for Isocratic RP-TLC and RP-AMD Separation}

Both separations were carried out on RP-silicagel plates. Methanolic solutions of rosmarinic acid $(1.08 \mathrm{mg} / \mathrm{mL})$, sinesetine $(6.00 \mathrm{mg} / \mathrm{mL})$ and eupatorine $(4.20 \mathrm{mg} / \mathrm{mL})$ were used as standards. $20 \mu \mathrm{L}$ of each sample and $10 \mu \mathrm{L}$ from each standard solution were applied as bands $(1 \mathrm{~cm})$ using an 
automated applicator. Isocratic elution was performed in normal chamber using the mixture acetonitrile - water - acetic acid (55:44:1, v/v) as mobile phase. The developing distance was $8 \mathrm{~cm}$. Gradient elution for RP-AMD was performed in 12 steps, on $8 \mathrm{~cm}$ (final developing distance), with acetonitrile - water - acetic mixtures of different composition, starting with the most polar one (Table 4).

Table 4. Mobile phase for AMD

\begin{tabular}{|l|c|c|c|c|c|}
\hline Bottle no. & 1 & 2 & 3 & 4 & 5 \\
\hline Steps no. & $1-2$ & $3-4$ & $5-6$ & $7-9$ & $10-12$ \\
\hline Water & 79 & 69 & 59 & 49 & 39 \\
\hline Acetonitrile & 20 & 30 & 40 & 50 & 60 \\
\hline Acetic acid & 1 & 1 & 1 & 1 & 1 \\
\hline
\end{tabular}

The scanning densitometry of the plates was performed at $254 \mathrm{~nm}$ and at $400 \mathrm{~nm}$ in fluorescence mode (excitation wavelength $-365 \mathrm{~nm}$ ). The in situ UV-Vis spectra of sinesetin, eupatorin and rosmarinic acid spots from standards and extracts were obtained in the range of $200-500 \mathrm{~nm}$.

The quantitative analyses were performed using calibration curves of three standards determined in the same chromatographic conditions as the isocratic analyses were performed. All determinations were made in triplicate and the result is the average of the individual values.

\section{REFERENCES}

1. H. List, L. Horhammer, „Hagers Handbuch der Pharmazeutischen Praxis“, Springer Verlag, Berlin, Vol. 5: Drogen E-O, 1993, 967.

2. M. Wichtl, „Herbal Drugs and Phytopharmaceuticals“, Medpharm Scientific Publishers, Stuttgart, 1994, 358.

3. P. Gorecki, E. Segiet-Kujawa, A. Mscisz, B. Zygmunt, Herba Polonica, 1999, 45(3), 179.

4. W. Sumaryono, P. Proksch, V. Wray, L. Witte, T. Hartmann T., Planta Medica, 1991, 57, 176.

5. P.G. Pietta, P. L. Mauri, C. Gardana, A. Bruno, Journal of Chromatography, 1991, $547,439$.

6. H. Wagner, S. Bladt, E.M. Zgainski, „Drogenanalyse“, Springer-Verlag, Berlin, 1983, 169.

7. L. Gracza, P. Ruff, Archive Pharmazie (Weinheim), 1984, 17, 339.

8. E. Wollenweber, K. Mann, Planta Medica, 1985, 51, 459. 
N.-K. OLAH, D. HANGANU, E. BODOKI, R. OPREAN, C. TOMA, C. MORGOVAN, E. CHIȘE, A. BRAȘOVAN, S. C. A. COBZAC, S. GOCAN

9. K.E. Malterud, I.M. Hanche-Olsen, I. Smith-Kielland, Planta Medica, 1989, 55, 569.

10. K. Burger, Fresenius Zeitung Analitische Chemie, 1984, 318, 228.

11. D.E. Jänchen, "Instrumental Multiple Development of High-Performance ThinLayer Chromatograms", Kaiser, R. E. Ed.;Proc. Of the $3^{\text {rd }}$ Int. Symp. on Instr. HPLC, Wüerzburg, Bad Düerkheim. 1985, 83.

12. D.E. Jänchen, H.J. Issaq, Journal of Liquid Chromatography, 1988, 11, 1941

13. M.F.M. Trysteen, R.G.e. Van Severen, B.M.J. De Spiegeleer, Analyst, 1989, 114, 1021.

14. S. Ebel, S. Völkl, Deutsche Apotheke Zeitung, 1990, 130, 2162.

15. S. Gocan, G. Cîmpan, L. Mureşan, Journal of Pharmaceutical and Biomedical Analysis, 1996, 14, 1221.

16. G. Matysik, E. Wojtasik, Journal of Planar Chromatography, 1994, 7, 34.

17. G. Matysik, Journal of Planar Chromatography, 1992, 5, 146.

18. J. Pothier, N. Galand, Journal of Chromatography A, 2005, 1080(2), 186.

19. C. Poole, Chapter 4. Automated Multiple Development, "Instrumental Thin-Layer Chromatography", Elsevier, Amsterdam, Boston, Heidelberg, London, New York, Oxford, Paris, San Diego, San Francisco, Singapore, Sydney, Tokyo, 2015, 73.

20. Sz. Nyiredy, Chromatographia, 2000, 51, S-288.

21. N.K. Olah, D. Hanganu, R. Oprean, C. Mogoșan, N. Dubei, S. Gocan, Journal of Planar Chromatography, 2004, 17(1), 18. 